Diabetologia 11, 135-138 (1975)

(c) by Springer-Verlag 1975

\title{
The Incidence of Diabetes Mellitus in the Offspring of Diabetic Couples Investigation Based on the Oral Glucose Tolerance Test
}

\author{
J. K. Radder and J. Terpstra \\ Diabetes Unit of the Department of Diseases of Metabolism and Endocrinology, University Hospital, Leiden, The Netherlands
}

Received: September 23, 1974, and in revised form: December 23, 1974

\begin{abstract}
Summary. 88 of 137 offspring of 22 adult onset diabetic couples were subjected to an oral glucose tolerance test (G.T.T.); 35 were found to have a diabetic G.T.T. As 8 were already known as diabetics, 43 of 96 offspring (45\%) were found to have diabetes mellitus. Neither the data pertaining to the parents, such as family history, treatment of diabetes or obstetric history, nor the data pertaining to the offspring, such as sex, age, parity or course of pregnancy, could be related to the incidence of diabetes in the offspring. It was
\end{abstract}

noted however, that overweight female, but not male, offspring are more likely to develop diabetes than those who are not overweight $(p<0.05)$.

Key words: Incidence of diabetes, offspring of adult onset diabetic couples, glucose intolerance, oral glucose tolerance test, heredity, inheritance, sex, age, body weight, family history of diabetes, treatment of diabetes, obstetrical history.
The mode of inheritance of diabetes mellitus is unknown, although the hereditary nature of the disease is generally accepted. If the genetic transmission is autosomal recessive, as has been assumed [1], the incidence of diabetes mellitus in the offspring of connubial diabetics would be $100 \%$, except in the case of incomplete penetrance. However, according to a recent review of the literature by Rimoin [2], a maximum of about $50 \%$ has been reported so far. No conclusions can be drawn from Rimoins' data concerning the pattern of inheritance of diabetes mellitus.

In this paper we present our findings in the offspring of diabetic couples. In contrast to others $[3,4,5]$ we tried to investigate all the offspring of diabetic couples. As far as we know this has only been done by Kahn [6]. We also made an attempt to relate some data pertaining to the parents to the incidence of diabetes in the offspring.

\section{Materials and Methods}

The offspring of 22 couples with proven adult onset [7] diabetes mellitus were examined.

Of the total of 137 offspring, $15 \mathrm{had}$ died and 26 (14 men and 12 women) did not participate in the study for various reasons, such as inability or unwillingness. None of these 41 persons was known to have or have had diabetes. 8 of the remaining 96 individuals ( 4 men and 4 women) had already been diagnosed as diabetic. They were all receiving dietary therapy and one alsotook an oral hypoglycaemicagent. There were no indications of other major diseases.
The remaining 88 subjects ( 40 men and 48 women, ranging in age from 15 to 58 years) underwent an oral glucose tolerance test (G.T.T.) with a $100 \mathrm{~g}$ glucose load following the normal precautions [8,9]. Blood samples were taken every half hour from the finger tip and the blood sugar was determined by the method of Nelson and Somogyi $[10,11,12]$.

We set the following upper limits for a normal G.T.T.: fasting value $100 \mathrm{mg} / 100 \mathrm{ml}$, maximum value $180 \mathrm{mg} / 100 \mathrm{ml}$ and $2 \mathrm{hr}$ value $140 \mathrm{mg} / 100 \mathrm{ml}$. These criteria are based on those of Fajans and Conn [13] and on our own findings in normals. The diagnosis of diabetes mellitus was made when two or more values of the oral G.T.T. exceeded our criteria of normality. Our classification of diabetes mellitus is in accordance with that of the British Diabetic Association [14].

We performed no test, other than questioning, to confirm that the subjects were incleed the offspring of the diabetic parents.

Of the 44 parents, 24 were under control in our out-patient department, the rest elsewhere. The mean age at the time of diagnosis of diabetes in the parents was 61 years with a range of $38-75.20$ parents had a family history of diabetes, 23 did not; for one female parent no data were available. 18 parents were treated with a diet, 20 with a diet and an oral hypoglycaemic agent and 6 with a diet and insulin. Of the female parents, 13 were delivered of one or more heavy-fordate babies ${ }^{1} ; 3$ of them had also had one or more stillbirths; for 1 female parent the course of pregnancies was unknown.

\footnotetext{
1 A baby weighing $4 \mathrm{~kg}$ or more at birth.
} 
The offspring were divided into two age groups: younger than 40 years and 40 years or older.

Overweight was defined as $120 \%$ of ideal body weight or more. The percentage of ideal body weight was calculated according to the Metropolitan Life Insurance Company tables [15].

Of the 48 female offspring, 8 were nulliparous; for the 40 other females the mean parity was 3 with a range of $1-13$; however, a parity of 2 was the most common (1.6 times). 6 female offspring had had one or more abortions; 8 gave birth to a heavy-for-date baby; 2 had had a stillbirth and 1 an immature delivery; 2 showed a combination of abortions and heavyfor-date babies and 1 a combination of an abortion, a heavy-for-date baby and a stillbirth.

Statistical analysis of the data was performed according to various conventional methods $[16,17,18]$. In analysing the data we had to take into account that in our out-patient department significantly more parents were treated with a diet alone or with diet and insulin than with diet and oral hypoglycaemic agents $(p<0.025)$, while in parents under control elsewhere the reverse occurred.

\section{Results $^{2}$}

\section{Glucose Tolerance Test}

35 of the 88 G.T.T.'s (40\%) were diabetic.

The remaining 53 G.T.T.'s (60\%) were not diabetic according to our criteria. 26 persons (30\%) had a completely normal G.T.T. For the other $30 \%$ one of the G.T.T. values was abnormal.

\section{Parents}

No significant relationship could be found between either the family history or the treatment of diabetes in the parents or the course of pregnancies in the female parents on the one hand and the incidence of diabetes in the offspring on the other.

\section{Offspring}

No significant difference in the frequency of diabetes in the offspring could be found between the different families.

We were not able to find a statistically significant relationship between the various combinations of sex, age and body weight on the one hand and the incidence of diabetes on the other (Table 1). This might be due to the fact that there were relatively few subjects in comparison to the number of possible combinations.

2 Additional detailed informations are available on request from J. K. Radder.
However, young overweight females seem to be more likely to develop diabetes than old overweight females (67\% and 50\%, respectively); on the other hand young overweight men seem to be less likely to develop diabetes than old overweight men $(22 \%$ and $42 \%$, respectively). For men and women who are not overweight, the incidence of diabetes with regard to age was approximately the same.

Table 1. Distribution of sex, age, body weight and diabetes in the offspring

\begin{tabular}{cccccc}
\hline & \multicolumn{2}{c}{ male } & \multicolumn{2}{c}{ female } \\
& young & old & & young & old \\
\hline \multirow{2}{*}{$\begin{array}{c}\text { non-diabetic } \\
\text { not overweight }\end{array}$} & 8 & 5 & 12 & 4 \\
diabetic & 4 & 2 & 5 & 2 \\
overweight & non-diabetic & 7 & 7 & 5 & 5 \\
& diabetic & 2 & 5 & 10 & 5 \\
\hline
\end{tabular}

a see Materials and methods for definition of age, body weight and diabetes.

A statistically significant difference was only found when the incidence of diabetes was related to sex and body weight: more diabetes was detected in women who were overweight than in those who were not $(p<0.05)$. Such a difference could not be demonstrated in men. The use of oral contraceptive agents by 12 young women did not influence this result.

For the female offspring no statistically significant relationship could be found between either parity or an abnormal course of pregnancy on the one hand and the incidence of diabetes on the other. This result was not altered when we also took age and body weight into account.

\section{Discussion}

35 of the 88 from a total of 137 offspring of 22 adult onset diabetic couples were found to have a diabetic G.T.T. As 8 were already known as diabetics, 43 of 96 offspring, i.e. $45 \%$, were found to have diabetes mellitus. This is in accordance with Rimoins' data [2].

There were no typical juvenile onset diabetics in the offspring. Thus with respect to the type of diabetes our material is homogeneous: the parents as well as the offspring had the adult onset type of diabetes.

As far as we know, only the report of Kahn et al. [6] is comparable with this study insofar as they also tried to investigate all the offspring of diabetic couples. The only fact which they mention with regard to the 
parents is that the diabetes was not of a secondary type. In 155 of the 274 offspring of 80 diabetic couples they performed 280 oral G.T.T.'s. This means that the G.T.T. must have been repeated at least once in many subjects. $33 \%$ of the 280 G.T.T.'s were found to be abnormal. They mentioned that when the oral G.T.T. was performed three times in 23 subjects, 26 , 22 and $30 \%$ had abnormal G.T.T.'s. Because of the good reproducibility of the oral G.T.T. within a group [19], this finding is to be expected. However, the poor reproducibility of the oral G.T.T. per individual [19] means that the method used by these authors to calculate the frequency of diabetes is not justifiable. They detected 6 cases of diabetes with the initial G.T.T., 3 additional cases with the second test and 4 more on completion of the third test. In this way they found 13 cases of diabetes in 23 subjects, in their words an "overall frequency" of diabetes of 57\%.

Other reports in the literature are not comparable. One study [3] does not state how many families and how many offspring of these families were investigated. In other investigations, the offspring of diabetic couples were selected via a known, typical, juvenile onset diabetic sibling [4] or they were studied together with the non-diabetic counterparts of identical diabetic twins [5].

In this study we tried to find a relationship between several parameters of the parents as well as of the offspring on the one hand and the incidence of diabetes mellitus in the offspring on the other. This could only be demonstrated for overweight and diabetes in the female offspring. In the male offspring a similar relationship could not be established. For many years diabetes mellitus has been associated with obesity [20]. It is possible, however, that the discrepancy we found between the sexes is caused by the fact that overweight, as defined in this report, is not synonymous with obesity [21], particularly in young males.

In contrast to others $[22,23,24,25,26]$ we did not find a relationship between the incidence of diabetes in the offspring and their age, parity or course of pregnancy. However, our test subjects may still be too young or our group too small.

From our study it is not possible to draw any conclusions with respect to the mode of inheritance of diabetes mellitus. The $45 \%$ incidence of diabetes found for the offspring of diabetic couples provides no clue as to the pattern of inheritance of diabetes mellitus. Even autosomal recessive transmission of diabetes mellitus characterized by oral glucose intolerance cannot be excluded, because the incidence of diabetes in the offspring may increase with age, eventually up to the expected $100 \%$. Testing glucose tolerance in some way other than orally seems to make no dif- ference as far as the detection of diabetes mellitus is concerned $[2,6]$.

It is also possible that glucose tolerance tests are not sensitive enough to detect diabetes mellitus in all cases. It is then necessary to look for a more sensitive and perhaps more basic marker of diabetes mellitus. In this respect some have stressed the importance of a decreased insulin secretion $[27,28,29,30]$ and an increased growth hormone release [31, 32]; others refer to capillary basal membrane thickening [33]. However, these findings have not been confirmed $[34,35,36$, $37]$ and the interpretations have also been criticized $[38,39]$.

Further investigation of the offspring of diabetic couples in the future may possibly give some indication for the mode of inheritance of diabetes mellitus.

Acknowledgements. We owe thanks to Dr. F. M. Gerritzen, Dr. J. D. Mulder and Dr. R. Vink for helping us select our patient material, Drs. E. A. v.d. Velde for statistical analysis, Mrs. A. Cornelius - von Franquemont for technical assistance, Miss M. G. A. T. Paal for secretarial help and Mrs. G. P. Bieger - Smith for correcting the English text. The Organization for Health Research T.N.O. lent financial support.

\section{References}

1. Pincus, G., White, P.: On the inheritance of diabetes mellitus. III The blood sugar values of the relatives of diabetics. Amer. J. med. Sci. 188, 782-790 (1934)

2. Rimoin, D. L.: Inheritance in diabetes mellitus. Med. Clin. N. Amer. 55, 807-819 (1971)

3. Ricketts, H. T., Cherry, R. A., Kirsteins, L.: Biochemical studies of "prediabetes". Diabetes 15, 880-888 (1966)

4. Burkeholder, J. N., Pickens, J. M., Womack, W. N.: Oral glucose tolerance test in siblings of children with diabetes mellitus. Diabetes 16, 156-160 (1967)

5. Taton, J., Pometta, D., Camerini-Dávalos, R. A., Marble, A.: Genetic determinism to diabetes and tolerance to glucose. Lancet 1964 II, 1360-1362

6. Kahn, C. B., Soeldner, J. S., Gleason, R. E., Rojas, L., Camerini-Dávalos, R. A., Marble, A.: Clinical and chemical diabetes in offspring of diabetic couples. New Engl. J. Med. 281, 343-347 (1969)

7. Wld HIth Org. techn. Rep. Ser.: Diabetes mellitus. Report of a WHO Expert Committee 310, 13-15 (1965)

8. Wld Hith Org. techn. Rep. Ser.: Diabetes mellitus. Report of a WHO Expert Committee 310, 9-10 (1965)

9. Bruins Slot, J., Sande, P. L. M. van de, Terpstra, J.: Diabetes mellitus and pregnancy. Folia med. neerl. 10, 7784 (1967)

10. Nelson, N.: A photometric adaptation of the Somogyi method for the determination of glucose. J. biol. Chem. 153, 375-380 (1944)

11. Somogyi, M.: A new reagent for the determination of sugars. J. biol. Chem. 160, 61-68 (1945)

12. Somogyi, M.: Determination of blood sugar. J. biol. Chem. 160, 69-73 (1945)

13. Conn, J. W.: The prediabetic state in man. Definition, interpretation and implications. Diabetes 7, 347-357 (1958) 
14. FitzGerald, M. G., Keen, H.: Diagnostic classification of diabetes. Lancet 1964 I, 1325-1326

15. Wissenschaftliche Tabellen, 7th edition, p. 701. Basel: J. R. Geigy A.G., Pharma 1968

16. Jonge, $H$. de: Inleiding tot de Medische Statistiek, part 1 and 2, 2nd edition. Groningen: Wolters Noordhoff 1963

17. Armitage, P.: Statistical methods in medical research, 1st edition. Oxford-Edinburgh: Blackwell Scientific Publications 1971

18. Cox, D. R.: Analysis of binary data, 1st edition. London: Methuen \& Co. 1970

19. McDonald, G. W., Fisher, G. F., Burnham, C.: Reproducibility of the oral glucose tolerance test. Diabetes 14, $473-480$ (1965)

20. Malins, J. M.: Diabetes in the population. Clin. in Endocr. and Metab. Diabetes and related disorders. 1, 647-648 (1972)

21. Kalkhoff, R., Ferrou, C.: Metabolic differences between obese overweight and muscular overweight men. New Engl. J. Med. 284, 1236-1239 (1971)

22. Pyke, D. A.: The incidence of diabetes and its preponderance among women. Acta genet. (Basel) 7, 91 - 96 (1957)

23. Fitzgerald, M. G., Malins, J. M., O'Sullivan, D. J., Wall, M.: The effect of sex and parity on the incidence of diabetes mellitus. Quarterly J. Med., New Series XXX 117, $57-70$ (1961)

24. Middleton, G. D., Caird, F. I.: Parity and diabetes mellitus. Brit. J. prev. soc. Med. 22, 100-104 (1968)

25. Malins, J. M., FitzGerald, M. G.: Childbearing prior to recognition of diabetes. Recollected birth weights and stillbirth rate in babies born to parents who developed diabetes. Diabetes 14, 175-178 (1965)

26. Malins, J. M.: Diabetes in the population. Clin. in Endocr. and Metab. Diabetes and related disorders. 1, 651-655 (1972)

27. Rojas, L., Soeldner, J. S., Gleason, R, E., Kahn, C. B., Marble, A.: Offspring of two diabetic parents: Differential serum insulin responses to intravenous glucose and tolbutamide. J. clin. Endocr. 29, 1569-1579 (1969)

28. Colwell, J. A., Lein, A.: Diminished insulin response to hyperglycemia in prediabetes and diabetes. Diabetes 16, $560-565$ (1967)

29. Serrano-Rios, M., Ramos, F., Rodriguez-Miñón, J. L., Vivanco, F.: Studies in prediabetes. Insulin response to oral glucose, intravenous tolbutamide and rapid intra- venous glucose infusion in genetic prediabetics. Diabetologia 6, 392-398 (1970)

30. Cerasi, E., Luft, R.: Insulin response to glucose infusion in diabetic and non-diabetic monozygotic twin pairs. Genetic control of insulin response? Acta endocr. (Kbh.) $\mathbf{5 5}, 330-345$ (1967)

31. Boden, G., Soeldner, J. S., Gleason, R. E., Marble, A.: Elevated serum human growth hormone and decreased serum insulin in prediabetic males after intravenous tolbutamide and glucose. J. clin. Invest. 47, 729-739 (1968)

32. Sönksen, P. H., Soeldner, J. S., Gleason, R. E., Boden, G.: Abnormal serum growth hormone responses in genetically potential-diabetic male patients with normal oral glucose tolerance: Evidence for an insulin-like action of growth hormone in vivo. Diabetologia 9, 426-437 (1973)

33. Siperstein, M. D., Unger, R. H., Madison, L. L.: Studies of muscle capillary basement membranes in normal subjects, diabetic and prediabetic patients. J. clin. Invest. 47, 1973-1999 (1968)

34. Jackson, W. P. U., Mieghem, W. van, Keller, P.: Insulin excess as the initial lesion in diabetes. Lancet $1972 \mathrm{I}$, 1040-1044

35. Radder, J. K., Terpstra, J.: Patterns of immunoreactive insulin and blood sugar values in latent diabetics. VIII Congress of the International Diabetes Federation, Abstracts. Excerpta Medica 280, 37 (1973)

36. Amherdt, M., Scherrer, J. R., Rufener, C., Pometta, D.: Early capillary changes in diabetes mellitus. Acta diab. lat. 8, Suppl. 1, 88-114 (1971)

37. Nikkels, R. E., Terpstra, J.: Capillary basement membrane thickness in early stages of diabetes mellitus. Diabetologia 9, 84-85 (1973)

38. Reaven, G. M., Shen, S. W., Silvers, A., Farquhar, J. W.: Is there a delay in the plasma insulin response of patients with chemical diabetes mellitus? Diabetes 20, 416-423 (1971)

39. Johansen, K.: Plasma-insulin levels during oral glucose loads in prediabetic subjects. Lancet 1973, I, 1443-1444
J. K. Radder, M.D.
Diabetes Department
University Hospital
Rijnsburgerweg 10
Leiden 2405
The Netherlands 